\title{
Perspectivas medioambientales en Melilla
}

\author{
José Manuel Cabo Hernández
}

\section{Una delimitación necesaria para empezar}

Utilizar el término medio ambiente (M.A. en adelante), resulta peligroso por su ambigüedad dada la multitud de aspectos que engloba. Como primer punto parece necesario concretar el término y delimitar los temas que se van a tratar en esta conferencia.

Podemos definir el medio ambiente como las condiciones físicas, químicas y biológicas que rodean a un organismo. El instrumento más útil para evaluar el M.A. es el de la ciencia ecológica que estudia las relaciones mutuas entre esas condiciones y los organismos y la de éstos entre sí.

Todo el conjunto de interrelaciones resulta demasiado denso y extenso como para ser analizado en el escaso tiempo de que disponemos, por eso vamos a concretar nuestro análisis en función del contexto de Jornadas, que a la vista del resto de las conferencias aparece con un marcado acento "naturalístico". Sin embargo al incluir al hombre en el análisis es imposible obviar determinadas cuestiones de ecología humana. Además algunos aspectos que influyen en la vida humana y que no son analizados aparecerán por su influencia en otros temas, como el Plan General de Ordenación Urbana (P.G.O.U.) o la Sanidad Pública.

\section{Impacto ambiental del medio urbano en los ecosistemas}

Los residuos urbanos presentan distinta problemática según se traten de sólidos, líquidos o gaseosos por ello se analizarán por separado.

A) Desechos gaseosos. Debido a la ausencia de industrias, desde la eliminación del vertedero incontrolado la fuente principal de contaminación son los humos de los coches, pero con las cantidades actuales de humos y el régimen de vientos de Melilla esto no supone un problema.

No obstante cabe hablar de la posible contaminación radiactiva en Melilla que procede de los pararrayos radiactivos. El caso de los pararrayos radiactivos es el siguiente: el Ministerio de Industria después de consultar al Consejo de Seguridad Nuclear publicó un Real Decreto en el que prohibía la fabricación de modelos de pararrayos con cabezales radiactivos y abrió un plazo de 1 año a partir de la publicación del Decreto para que los propietarios de pararrayos de este tipo los desmontaran utilizando a las empresas autorizadas por el Estado para instalaciones radiactivas o bien los dotaran de instalaciones de seguridad. El plazo terminó el 13 de junio del pasado año 1987, y el grado de cumplimiento del Real Decreto es muy escaso. La prohibición del uso de estos pararrayos se debe a la radiactividad que emiten especialmente cuando envejecen, sin que este dispositivo suponga una ventaja apreciable sobre los pararrayos 
convencionales. La dificultad del cumplimiento del Decreto viene de la pereza de los propietarios en gastar dinero en las empresas autorizadas y en la desinformación sobre la existencia del Decreto. En Melilla existen pararrayos de este tipo muchos de ellos en edificios públicos, por lo que una acción coordinada de todos los organismos que los poseen junto con los particulares pucde abaratar la operación si todos utilizan a la misma empresa.

B) Residuos sólidos. Están compuestos por basuras domésticas e industriales y por escombros. Hasta hace poco estos residuos cran climinados por el vertedero municipal. Los efectos de este vertedero en los ecosistemas eran los siguientes:

- Contaminación atmosférica, por los humos, olores y cenizas en suspensión que eran más o menos patentes según las condiciones meteorológicas.

- Contaminación en el mar, producida por los desechos que caían en el mar y que eran transportados por las corrientes en un segmento de costa variable según el estado del mar, que también los depositaban en las playas. Además se producía contaminación por aporte de materia orgánica que caía al mar o era arrastrada por las lluvias y, por su cantidad, no era biodegradada por los microorganismos recicladores, lo que producía eutrofización: disminución del oxígeno disuelto en agua y la eliminación de las cadenas tróficas con el consiguiente empobrecimiento de los ecosistemas. A esta situación se añadía el hecho de la imposibilidad de utilizar ese sector de costa para esparcimiento como está previsto en el P.G.O.U. con la construcción de la carretera de Aguadú. Por todo ello se buscaron alternativas, el Cuadro I resume las alternativas más importantes. La solución elegida fue la planta incineradora como es sabido. El tratamiento por

\begin{tabular}{|c|c|}
\hline \multicolumn{2}{|c|}{ CUADRO I } \\
\hline \multicolumn{2}{|c|}{ Vertedero controlado } \\
\hline $\begin{array}{l}\text {-Poco gasto inicial } \\
\text {-Reutilización de la superficie ocupada }\end{array}$ & $\begin{array}{l}\text { - Necesita mucha superficie } \\
\text { - Produce contaminación en caso } \\
\text { de mantenimiento inadecuado }\end{array}$ \\
\hline \multicolumn{2}{|c|}{ Planta incineradora } \\
\hline $\begin{array}{l}\text {-Poca superficie } \\
\text {-Nula contaminación } \\
\text { - Puede obtenerse electricidad del gas }\end{array}$ & $\begin{array}{l}\text {-Gasto elevado } \\
\text { - Necesita un vertedero controlado anexo } \\
\text { para las cenizas y para casos de } \\
\text { averías y paradas técnicas }\end{array}$ \\
\hline \multicolumn{2}{|r|}{ Reciclaje } \\
\hline $\begin{array}{l}\text { Elimina los residuos por } \\
\text { reutilización de métales, plásticos, } \\
\text { vidrio y materia orgánica }\end{array}$ & $\begin{array}{l}\text {-Necesita una industria anexa } \\
\text { y un mercado para } \\
\text { introducir los productos } \\
\text { reciclados }\end{array}$ \\
\hline
\end{tabular}

reciclaje tiene el problema de necesitar una industria cercana que recicle los desechos, inexistente en Melilla con las carencias de iniciativa privada y con el problema de la 
comercialización de estos productos, por lo que la planta incineradora parece la solución más racional; además no descarta para el futuro la recogida por separado de los desechos y el consiguiente reciclaje con la puesta en funcionamiento del Polígono Industrial.

Las actuaciones para el futuro en este campo se centran en la localización del vertido de escombros que se pueden utilizar para relleno y nivelación de futuras zonas verdes. También es preciso construir un vertedero controlado de pequeñas dimensiones para solucionar los problemas de acumulación de cenizas de la planta y para poder almacenar la basura en caso de parada técnica o avería que con el paso del tiempo serán más probables. Por fin es necesario la recuperación del antiguo vertedero actualmente utilizado para escombros, necesario para la utilización pública de la zona.

C) El ciclo del agua en Melilla. La salida del agua residual al mar por distintos colectores producía contaminación orgánica como en el caso anterior, más contaminación bacteriológica, lo que suponía un problema grave en la utilización del agua para baños. Por ello se creó la Planta Depuradora de Aguas residuales que resolvía este problema.

Los problemas actuales con el agua no son los de la contaminación pues con la terminación de la red de saneamiento y el enganche de toda la red a la Planta Depuradora, la acción contaminante está controlada, sino en la obtención del agua y en la calidad de las mismas. El Cuadro II resume la problemática del agua en Melilla. Esta situación

\section{CUADRO II \\ Problemática del agua en Melilla}

\section{EN LA OBTENCION}

- 6 de los sondeos superan los límites de tolerabilidad en $\mathrm{Cl}^{-}$y sólidos disueltos.

- Existe problema de sobreexplotación en 6 sondeos.

- No se conoce la potencia de las 6 captaciones de terrenos volcánicos por lo que no sabemos hasta cuando se podrá seguir profundizando los pozos.

\section{EN LA DISTRIBUCION}

- Pérdidas reconocidas del $10 \%$ en la distribución desde los Depósitos Generales hasta las casas. Evaluación definitiva de las pérdidas, por realizar.

- Diferencias de presión que producen exceso de gasto.

- Diámetros no adecuados.

\section{EN EL CONSUMO}

- Despilfarro del uso de agua doméstica.

- Instalaciones que gotean, "grifos que gotean". 
hace imposible asegurar con los medios actuales el abastecimiento de agua a medio y largo plazo. Existen 3 posibilidades para el futuro: la búsqueda de nuevos acuíferos para lo cual se ha encargado un estudio geológico que no se conocerá hasta dentro de un año, la utilización de una planta desalinizadora de agua de mar y por último traer el agua en aljibes desde la península que en este momento es la solución más probable. Los proyectos que el MOPU ha previsto en este sentido son los siguientes:

- Traer agua de pantanos de la península que es transportada por tubería desde el puerto hasta unos depósitos intermedios donde es potabilizada.

- Construir unos nuevos depósitos generales de agua de mayor capacidad que los actuales para responder a la demanda de agua en el futuro.

- Construcción de una presa en el Río Nano como depósito accesorio de reserva con su Planta Potabilizadora.

Estas medidas aseguran el abastecimiento de agua en el futuro y solucionan el problema de la calidad del agua. La situación a corto plazo depende del mantenimiento de los aforos actuales hasta la realización de los proyectos previstos. En este período de tránsito puede ocurrir que los aforos actualmente sobreexplotados y de mejor calidad disminuyan, lo que no solo disminuye el agua disponible sino que empeora la calidad. Actualmente se suministran en teoría más de 200 litros/hab./día, por lo que queda un margen para que aunque disminuya esta cifra exista el mínimo indispensable. En el caso del empeoramiento de la calidad del agua de forma permanente cabe la posibilidad de poner en funcionamiento una Planta de Osmosis Inversa que actualmente no se utiliza por su costo de mantenimiento y por su capacidad reducida, aunque puede garantizar la calidad del agua de las fuentes públicas si debido a la escasez de agua de Trara fuera necesario abastecer a estas fuentes con agua de la red general. En cualquier caso no se pueden olvidar 3 actuaciones complementarias:

A) La reparación o sustitución de la red de distribución en el caso de que la evaluación de las pérdidas sea superior a más del $10 \%$, consideradas como normales. La importancia de esta medida se comprende si se evalúa económicamente esa pérdida. De acuerdo a estimaciones de 1985 , el $10 \%$ suponen a 60 ptas. el m ${ }^{3}$ unas 146.700 ptas. diarias, lo que al cabo de un año suma alrededor de 53,5 millones. En 1992 y con un precio entre 100 y $160 \mathrm{ptas} / \mathrm{m}^{3}$ del agua importada, estas pérdidas en un año oscilarán entre 89 millones y 142 millones.

B) El desarrollo de una campaña de información pública realista como base para cambiar hábitos derrochadores de agua en la población, sin excluir medidas extraordinarias en la época de verano que limiten el agua de utilización privada no imprescindible (piscinas, riego de jardines particulares...).

C) La salida de aguas residuales se realiza por la Planta Depuradora de la Hípica a través de un emisario submarino. En este momento existe un proyecto de reciclaje de aguas residuales depuradas para riego. El proyecto prevee el regadío en casi $250 \mathrm{Ha}$. de las cuales la mayoría están en huertas privadas. Las exigencias sanitarias de las aguas residuales dependen del tipo de técnica de riego y del tipo de cultivo al que se dediquen. Además no existe una legislación en este campo uniforme en todos los países. Por ejemplo para el consumo de productos crudos por el hombre no se pueden utilizar este tipo de aguas en Israel, salvo que se trate de fruta que se coma pelada. En California sin embargo se fijan medidas distintas según el tipo de riego. Para el riego por 
aspersión que es el previsto en Melilla, se autoriza utilizando el filtrado y la desinfección que son tratamientos previstos en nuestro proyecto aunque añade una coagulción previa que no está en Melilla. De todas formas las cosechas que no sean de consumo humano o que se consuman cocidas pueden ser regadas con aguas residuales tratadas con las medidas previstas aquí. Los problemas reales de este proyecto no son de orden ecológico pues existen salidas técnicas para superarlos, sino el hecho de que vaya a ser utilizado por la iniciativa privada que debe responder con inversiones. A la falta de iniciativas privadas en Melilla, este sector añade la competividad de los productos marroquíes por lo que el éxito del proyecto pasa por un estudio de mercado sobre la comercialización de los productos que de alguna manera asegure las inversiones necesarias. Hasta el momento ese estudio no es conocido.

\section{La Conservación de la Naturaleza}

Existen temáticas totalmente distintas, la de la orla periurbana de Melilla y la de las islas Chafarinas.

Conservación de las Chafarinas. Con independencia de si las islas formarán parte del territorio autonómico de Melilla o no, éstas seguirán dependiendo de Melilla a través de distintos organismos, de la Junta de Obras del Puerto, del MOPU, del personal civil contratado por el Ejército y de la Compañía de Mar de Melilla, además de los lazos históricos y culturales que unen las islas con Melilla. Por ello debe salir de nuestra ciudad la iniciativa de protección de las Chafarinas como espacio natural. Las razones de esa protección se justifican por la presencia en ellas de la mayor colonia del mundo de una especie de gaviota, la de Pico Rojo, que además es la gaviota más amenazada de extinción. Tambićn se reproduce en la isla del Congreso la Pardela Cenicienta que es un ave marina de población posiblemente en disminución y que en España, salvo en Canarias, sólo se reproduce en las Baleares, Columbretes y Chafarinas. A estas dos especies de suma una de las colonias más grandes del Mediterráneo de Gaviota Argéntea con más de 5.000 parejas. Otras especies de interés son el Aguila Pescadora y la Foca Monje, lo que recuerda que a la riqueza de aves de ámbito terrestre hay que añadir el valor del medio subacuático por lo que el régimen de protección debe extenderse a las aguas próximas a las islas. Por estas razones debe salir de Melilla la petición para que el ICONA inicie el expediente correspondiente y nadie mejor que el Ayuntamiento de la ciudad, en representacón de los melillenses para que se dirija al Ministerio de Agricultura con esta petición.

Conservación de la orla periurbana. En este ámbito caben dos tipos de actuaciones, sobre el biotopo en sí y sobre los seres vivos. Las actuaciones en el biotopo más que de conservación deben ser de regeneración pues dada la influencia humana no cabe hablar de zonas a conservar. En este sentido las actuaciones obedecen a la necesidad de evitar la erosión de las aguas superficiales salvajes y encauzadas mediante obras públicas de protección para lluvias potenciales y en una política de repoblación para fijación y regeneración del suelo que combine la introducción de especies autóctonas como el araar y el lentisco, con la creación de zonas de esparcimiento que debidamente equipadas permitan ambos fines, especialmente con la creación de nuevos viales periféricos (pista de carros) previstos en el PGOU y que proporcionarán acceso a nuevas zonas de 
la ciudad a toda la población.

Conservación de la Fauna. La problemática en este campo se debe a la presencia en Melilla de especies protegidas por distintas normativas y que ante la ausencia de Servicios del ICONA en unos casos y el desconocimiento de los ciudadanos de esas normativas y de las razones que las justifican en otros casos, no presentan las garantías suficientes de conservación. Entre estos casos podemos citar los siguientes:

- Especies afectadas por el Convenio sobre el Comercio Internacional de Especies Amenazadas de Fauna y Flora silvestres (CITES) (B.O.E. 30.7.86). Entre las especies que se comercializan o se poseen en Melilla a pesar de la prohibición por este Convenio, se encuentran los monos, las tortugas y los camaleones.

- Especies afectadas por el Convenio relativo a la Conservación de la Vida Silvestre y del Medio Natural en Europa (B.O.E. 1.10.86) que completa los decretos españoles de especies protegidas (Real Decreto 3.181/80 de 30.12 y Real Decreto $1.497 / 86$ de 6.6). Entre las que son objeto de protección en estos decretos encontramos en Melilla el erizo moruno, las tortugas marinas, más de 50 especies de aves. En estos Decretos también se prohibe la utilización de trampas, redes, aves vivas, anzuelos, lazos; siendo éstos los métodos de caza más utilizados en Melilla además de las carabinas de aire comprimido. Posiblemente sorprenda la cantidad de aves protegidas presentes en Melilla. Esto se debe a la existencia de rutas migratorias a través del Cabo Tres Forcas que hace que en la época de paso las aves locales se vean incrementadas por especies migratorias. Este hecho es aprovechado por los cazadores a pesar de que la reglamentación de caza impide la práctica de ésta, por falta de medidas de seguridad

\section{CUADRO III}

\section{Conservación de la Naturaleza en Melilla}

\section{CONSERVACION DEL BIOTOPO}

- Regeneración del suelo.

- Control de las aguas superficiales.

- Repoblación con especies autóctonas.

\section{CONSERVACION DE LAS ESPECIES}

- Cumplimiento del Convenio sobre el Comercio Internacional de especies amenazadas de Fauna y Flora silvestres (CITES).

- Cumplimiento del Convenio relativo a la Conservación de la Vida Silvestre y del Medio Natural en Europa que completa la legislación española de especies protegidas.

- Cumplimiento de las normas de tamaño mínimo de captura de la pesca y especies de pesca prohibida. 
ante la proximidad de caminos, casas y senderos.

- Especies prohibidas de pesca o de tamaño mínimo de captura. Es el caso del chanquete y de los "pezqueñines" que se venden en los mercados públicos con regularidad.

Al no existir el servicio de ICONA, corresponde a la Guardia Civil la prohibición de la misma, al igual que el control fronterizo de especies procedentes de Marruecos. Con la aprobación definitiva de las Ordenanzas Municipales sobre zonas verdes la Policía Municipal tendrá plenas competencias en materia de caza ya que ésta está prohibida en las Ordenanzas. El control de las especies que entran por la Lonja corresponde a la Comandancia de Marina y al Servicio Veterinario del Ministerio de Sanidad. Las sanciones sobre comercialización y tenencia de especies vivas corresponde al Ministerio de Agricultura.

\section{A modo de conclusión}

Como resultado del análisis realizado se deducen una serie de conclusiones a modo de propuestas que son las siguientes:

1. Dado el volumen de temas y a la diversidad de ellos, la administración debería dotarse de una infraestructura material y personal mayor que la actual, especializando los servicios técnicos y ampliándolos con nuevos profesionales, por ejemplo biólogos.

2. Actualmente las competencias de medio ambiente se encuentran diseminadas entre los ministerios de Sanidad, MOPU, Agricultura, Defensa, Interior y por supuesto la Administración Local. Es necesario para conseguir una mayor eficacia que la Autonomía melillense se dote de un órgano único para la gestión del M.A. que planifique todas las actuaciones.

3. Ese órgano debería tener un carácter más técnico que político y para ello podría depender directamente de la Presidencia de la Autonomía, como en el caso andaluz.

4. Las actuaciones ante los ciudadanos no deben ser exclusivamente coactivas sino que deben potenciarse las campañas de información al consumidor, tanto para modificar comportamientos cívicos, como para el conocimiento de normas de obligado cumplimiento y las razones que las justifican.

5. Por último el Ayuntamiento debería iniciar contactos con el Ministerio de Agricultura para la tramitación de un expediente que dote a las Islas Chafarinas de un status de protección especial. 